\title{
Oral contraceptives and breast cancer: a national study
}

\author{
CHARLOTTE PAUL, D C G SKEGG, G F S SPEARS, J M KALDOR
}

\begin{abstract}
In a population based case-control study 433 New Zealand women aged $25-54$ with newly diagnosed breast cancer were compared with 897 women selected at random from the electoral rolls. The relative risk of breast cancer in women who had ever used oral contraceptives was 0.94 (95\% confidence interval 0.70 to $1 \cdot 25)$. The relative risk in women aged $25-34$ at diagnosis was estimated to be $2.2(95 \%$ confidence interval 0.47 to 9.9$)$ and in older women $<1$. Analyses of risk by duration of use of oral contraceptives, age at first use, and time since first use showed no adverse effect of the pill. In particular, there was no increased risk in women who had used oral contraceptives before the age of 25 or before their first pregnancy, even for prolonged periods.

Given the high prevalence of use in New Zealand, this study provides strong evidence against the hypothesis that use of oral contraceptives at young ages increases the risk of breast cancer.
\end{abstract}

\section{Introduction}

Oral contraceptives might be expected to affect a woman's risk of breast cancer, given the importance of hormonal and reproductive factors in the aetiology of the disease. ${ }^{1}$ Early studies were mostly reassuring, ${ }^{2}$ but three recent reports pointed to an increased risk of breast cancer associated with use of oral contraceptives at young ages. ${ }^{3-5}$ The negative results of the much larger cancer and steroid hormone study seemed to conflict with these reports. ${ }^{6}$ It has been suggested that this discrepancy might be due to different patterns of use of oral contraceptives in the various study populations: only in places where young women had a high prevalence of pill use 10 or 20 years ago could research confirm or refute the existence of a hazard.

New Zealand women have a history of exceptionally high use of the pill. In 1975 an estimated 35\% of women aged 15-45 were current users, compared with $19 \%$ in both the United Kingdom and the United States. ${ }^{8}$ We report results from a national case-control study of breast cancer in New Zealand women.

\section{Subjects and methods}

In this population based study all New Zealand women aged 25-54 in whom breast cancer had been diagnosed were eligible to serve as cases; control subjects were selected at random from the electoral rolls.

\section{CASES}

The National Cancer Registry (or, in the Auckland region, the Auckland Breast Cancer Study Group) identified 739 women aged 25-54 in whom a diagnosis of breast cancer (International Classification of Diseases, rubric 174) had been confirmed histologically between 1 July 1983 and 30 June 1985. Permission for the release of information was given by all superintend-

\section{Department of Preventive and Social Medicine, University of Otago,} Dunedin, New Zealand

CHARLOTTE PAUL, MB, MCCMNZ, senior lecturer in epidemiology D C G SKEGG, MB, DPHIL, professor

G F S SPEARS, MSC, DIPMATHLSTATS, senior lecturer in biostatistics

International Agency for Research on Cancer, Lyons, France

J M KALDOR, PHD, biostatistician

Correspondence to: Professor Skegg. ents of public hospitals and by all but four $(3 \cdot 7 \%)$ of the specialists responsible for private patients.

Patients were excluded from the study if breast cancer had been diagnosed previously, if their names were not in a current electoral roll, or if their telephone number could not be found. After these criteria had been applied 554 cases remained. We also required that patients be interviewed four to eight months after diagnosis; this resulted in the exclusion of a further 57 patients, of whom eight had died and 49 had been identified too late to be interviewed within eight months after diagnosis. Interviews were completed in $437(88 \%)$ of the 497 remaining cases. Sixty patients were not interviewed because their surgeon or general practitioner refused permission (28), because the patient herself refused to participate (14), because the patient was too ill (4), or for miscellaneous reasons (14).

After the interview a further four women were excluded because they were found to have had breast cancer diagnosed previously. Thus we finally studied 433 cases.

\section{CONTROLS}

In New Zealand electoral registration is compulsory for adults aged 18 and over. Control subjects were randomly selected from the electoral rolls, women whose telephone numbers could not be found being excluded. As age is not specified in the electoral rolls we had to choose more women than were required for the study. We wrote to these women requesting information about their age and seeking their participation. All controls were written to between 1 November 1983 and 31 October 1985. Of 2412 women sent letters, 973 were found to be outside the required age range (25-54). We randomly excluded half the potential controls under the age of 35 (303 women) to approximate the age distribution of the cases better. A further 39 subjects were excluded for other reasons: serious illness (4), death (10), absence overseas (12), or language difficulties (13). Of the remaining 1097 potentially eligible women, $923(84 \%)$ were interviewed. Ninety nine $(9 \%)$ refused to take part, and $75(7 \%)$ had not been traced, or had been traced but not interviewed, in time for inclusion in this report. About half of these untraced women would have been outside the age range for the study.

For each control a "reference date" was calculated by subtracting six months from the date of interview, to correspond to the mean time between diagnosis and interview among the cases. After the interview 26 women were excluded because of a history of breast cancer or because they were younger than 25 or older than 54 on the reference date. The final control group thus comprised 897 women.

\section{DATA COLLECTION}

Information was collected using identical methods for cases and controls. Women were interviewed by telephone after an initial approach by letter. The interview took about 20 minutes and sought details of medical, social, menstrual, and reproductive histories. Both letter and interview were designed so that they did not disclose the study hypotheses. All interviews were conducted by one nurse-interviewer $(93 \%)$ or one of us (CP). Most began with the interviewer being blind whether the subject was a case or control, although case patients generally reported their illness during the interview. To help recall of past contraceptive use our initial letter was accompanied by a calendar, on which women were asked to mark important dates such as marriages and births of children for reference during the interview. As a check on the interview method we also wrote to the general practitioners of women who reported recent use of prescribed contraceptives: there was close agreement between the contraceptive histories received from the general practitioners and from the women themselves.

\section{STATISTICAL ANALYSES}

For cases contraceptive use before the date of diagnosis was considered in the analyses. For controls the reference date was used. We used standard statistical methods for the analysis of case-control studies. Relative risks were estimated by calculating odds ratios, adjusted for age (in five year groups) by the method of Mantel and Haenszel. ${ }^{9}$ Confidence intervals were 
estimated by Cornfield's procedure ${ }^{10}$ as programmed by Thomas. ${ }^{11}$ When simultaneously adjusting for several risk factors we applied the multiple logistic model ${ }^{12}$ using the computer program GLIM. ${ }^{13}$ Age adjustment was again in five year groups, except for the analysis reported in table II, in which age was adjusted for as a continuous variable within each 10 year age group.

\section{Results}

Table I summarises characteristics of the cases and controls. The average age was higher among the cases. For all other variables the table gives relative risk estimates adjusted for age, with $95 \%$ confidence intervals. The risk of breast cancer was increased among women with an early menarche, a late age at first full term pregnancy, low parity, a history of surgery for benign breast disease, or a family history of breast cancer. Other potentially confounding variables examined included menopausal state, subfecundity, history of irregular menstruation, body mass index, ethnic group, geographical area of residence, social class, education, cigarette smoking, and alcohol consumption.

The proportions of cases and controls who had used oral contraceptives at some time were $71 \cdot 6 \%(310 / 433)$ and $78.9 \%(708 / 897)$, respectively. The relative risk for these ever users of the pill, adjusted for potentially confounding variables by logistic regression, was 0.94 (95\% confidence interval 0.70 to $1 \cdot 25$ ). Table II shows the relative risk of breast cancer according to the age at diagnosis and duration of use of oral contraceptives; risks are expressed relative to those for women in the same age group who had

TABLE I-Characteristics of 433 cases and 897 controls

\begin{tabular}{|c|c|c|c|c|}
\hline Characteristic & $\begin{array}{l}\text { No of } \\
\text { cases }\end{array}$ & $\begin{array}{l}\text { No of } \\
\text { controls }\end{array}$ & $\begin{array}{c}\text { Relative } \\
\text { risk }^{\star}\end{array}$ & $\begin{array}{l}95 \% \\
\text { confidence } \\
\text { interval } \dagger\end{array}$ \\
\hline $\begin{array}{l}\text { Age (years): } \\
25-29 \\
30-34 \\
35-39 \\
40-44 \\
45-49 \\
50-54\end{array}$ & $\begin{array}{r}11 \\
31 \\
59 \\
90 \\
124 \\
118\end{array}$ & $\begin{array}{r}96 \\
107 \\
163 \\
204 \\
169 \\
158\end{array}$ & & \\
\hline $\begin{array}{l}\text { Ethnic group: } \\
\text { Non-Maori } \\
\text { Maori }\end{array}$ & $\begin{array}{r}408 \\
25\end{array}$ & $\begin{array}{r}848 \\
49\end{array}$ & $\begin{array}{l}1 \cdot 0 \\
1 \cdot 2\end{array}$ & 0.69 to 2.0 \\
\hline $\begin{array}{l}\text { Age at menarche (years): } \\
\quad<12 \\
12-14 \\
\geqslant 15\end{array}$ & $\begin{array}{r}81 \\
279 \\
73\end{array}$ & $\begin{array}{l}138 \\
598 \\
161\end{array}$ & $\begin{array}{l}1.0 \\
0.75 \\
0.66\end{array}$ & $\begin{array}{l}0.54 \text { to } 1.0 \\
0.43 \text { to } 1.0\end{array}$ \\
\hline $\begin{array}{l}\text { Age at first full term pregnanc } \\
\text { Nulliparous } \\
<20 \\
20-24 \\
25-29 \\
\geqslant 30\end{array}$ & $\begin{array}{r}57 \\
48 \\
194 \\
97 \\
37\end{array}$ & $\begin{array}{r}103 \\
127 \\
426 \\
188 \\
53\end{array}$ & $\begin{array}{l}1.0 \\
0.66 \\
0.67 \\
0.69 \\
0.81\end{array}$ & $\begin{array}{l}0.39 \text { to } 1 \cdot 1 \\
0.45 \text { to } 1 \cdot 0 \\
0.43 \text { to } 1 \cdot 1 \\
0.43 \text { to } 1.5\end{array}$ \\
\hline $\begin{array}{l}\text { Parity: } \\
\text { Nulliparous } \\
1-3 \\
\geqslant 4\end{array}$ & $\begin{array}{r}57 \\
286 \\
90\end{array}$ & $\begin{array}{l}103 \\
569 \\
225\end{array}$ & $\begin{array}{l}1 \cdot 0 \\
0 \cdot 78 \\
0 \cdot 45\end{array}$ & $\begin{array}{l}0.53 \text { to } 1.2 \\
0.27 \text { to } 0.71\end{array}$ \\
\hline $\begin{array}{l}\text { Family history of breast cance } \\
\text { None } \\
\text { Second degree relative only } \\
\text { First degree relative }\end{array}$ & $\begin{array}{r}325 \\
66 \\
42\end{array}$ & $\begin{array}{r}775 \\
82 \\
40\end{array}$ & $\begin{array}{l}1 \cdot 0 \\
2 \cdot 1 \\
2 \cdot 4\end{array}$ & $\begin{array}{l}1.4 \text { to } 3.0 \\
1.5 \text { to } 4.0\end{array}$ \\
\hline $\begin{array}{l}\text { History of surgery for benign } \\
\text { No } \\
\text { Yes }\end{array}$ & $\begin{array}{r}376 \\
57\end{array}$ & $\begin{array}{r}828 \\
69\end{array}$ & $\begin{array}{l}1.0 \\
1.5\end{array}$ & 1.0 to 2.3 \\
\hline
\end{tabular}

*Mantel-Haenszel estimate, adjusted for age at diagnosis

tAdjusted for age at diagnosis.

TABLE II-Relative risk of breast cancer ${ }^{\star}$ according to total duration of use of oral contraceptives and age at diagnosis (relative to never users in each age group). Figures in parentheses are numbers of cases and controls

\begin{tabular}{lllll}
\hline \multirow{2}{*}{$\begin{array}{c}\text { Duration of } \\
\text { use (years) }\end{array}$} & \multicolumn{4}{c}{ Age at diagnosis (years) } \\
\cline { 2 - 5 } & $25-34$ & \multicolumn{4}{c}{$35-44$} & \multicolumn{1}{c}{$45-54$} & All ages \\
\hline$<2$ & $2 \cdot 8(12,43)$ & $0 \cdot 90(37,87)$ & $1 \cdot 3(58,59)$ & $1 \cdot 1(107,189)$ \\
$2-5$ & $1 \cdot 6(12,75)$ & $0.92(42,107)$ & $0.81(38,62)$ & $0.84(92,244)$ \\
$6-9$ & $1 \cdot 8(8,47)$ & $0.87(22,59)$ & $0.60(18,39)$ & $0.76(48,145)$ \\
$\geqslant 10$ & $4 \cdot 6(8,17)$ & $0.84(24,66)$ & $0 \cdot 96(31,47)$ & $0 \cdot 96(63,130)$ \\
\hline Total & $2 \cdot 2(40,182)$ & $0.91(125,319)$ & $0 \cdot 90(145,207$ & $0.94(310,708)$
\end{tabular}

^Adjusted for age (within each 10 year age group), age at menarche, age at first full term pregnancy, history of benign breast disease, family history of breast cancer, and ethnic group.
TABLE III-Relative risk of breast cancer ${ }^{\star}$ according to total duration of use of oral contraceptives and age at first use (relative to all never users). Figures in parentheses are numbers of cases and controls

\begin{tabular}{|c|c|c|c|c|}
\hline \multirow{2}{*}{$\begin{array}{r}\text { Duration of } \\
\text { use (years) }\end{array}$} & \multicolumn{4}{|c|}{ Age at first use (years) } \\
\hline & $<20$ & $20-24$ & $\geqslant 25$ & All ages \\
\hline$<2$ & $1.4(10,31)$ & $0.97(22,60)$ & $1 \cdot 2 \quad(75,98)$ & $1 \cdot 1<(107,189)$ \\
\hline $2-5$ & $0.59(9,61)$ & $1 \cdot 1 \quad(38,99)$ & $0 \cdot 78(45,84)$ & $0.84(92,244)$ \\
\hline $6-9$ & $0.96(9,42)$ & $0.86(18,57)$ & $0.64(21,46)$ & $0 \cdot 76(48,145)$ \\
\hline$\geqslant 10$ & $0.80(8,32)$ & $1 \cdot 3(27,50)$ & $0.82(28,48)$ & $0.96(63,130)$ \\
\hline Total & $0.84(36,166)$ & $1 \cdot 0(105,266)$ & $0.91(169,276)$ & $0.94(310,708)$ \\
\hline
\end{tabular}

*Adjusted for age, age at menarche, age at first full term pregnancy, history of benign breast disease, family history of breast cancer, and ethnic group.

TABLE IV-Relative risk of breast cancer ${ }^{\star}$ according to total duration of use of oral contraceptives and time since first use (relative to all never users). Figures in parentheses are numbers of cases and controls

\begin{tabular}{|c|c|c|c|c|}
\hline \multirow{2}{*}{$\begin{array}{l}\text { Duration of } \\
\text { use (years) }\end{array}$} & \multicolumn{4}{|c|}{ Time since first use (years) } \\
\hline & $<10$ & $10-14$ & $\geqslant 15$ & All \\
\hline $\begin{array}{l}<2 \\
2-5 \\
6-9 \\
\geqslant 10\end{array}$ & $\begin{array}{l}1 \cdot 5(14,31) \\
0.88(8,35) \\
0.65(2,18)\end{array}$ & $\begin{array}{l}1 \cdot 1(24,52) \\
0 \cdot 80(23,76) \\
0 \cdot 94(11,38) \\
1 \cdot 2(11,27)\end{array}$ & $\begin{array}{l}1 \cdot 1(69,106) \\
0 \cdot 87(61,133) \\
0 \cdot 72(35,89) \\
0.91(52,103)\end{array}$ & $\begin{array}{l}1 \cdot 1 \quad(107,189) \\
0 \cdot 84(92,244) \\
0 \cdot 76(48,145) \\
0.96(63,130)\end{array}$ \\
\hline Total & $1 \cdot 1 \quad(24,84)$ & $0.99(69,193)$ & $0.91(217,431)$ & $0.94(310,708)$ \\
\hline
\end{tabular}

^Adjusted for age, age at menarche, age at first full term pregnancy, history of benign breast disease, family history of breast cancer, and ethnic group.

TABLE V-Relative risk of breast cancer ${ }^{\star}$ according to duration of use of oral contraceptives before first full term pregnancy or before age 25 (relative to non-users in those periods). Figures in parentheses are numbers of cases and controls

\begin{tabular}{ccc}
\hline Duration of use (years) & Use before first pregnancy & Use before age 25 \\
\hline$<2$ & $0.89(60,147)$ & $1 \cdot 2(81,191)$ \\
$2-3$ & $0.83(26,82)$ & $0.98(44,141)$ \\
45 & $0 \cdot 71(11,41)$ & $0.65(11,65)$ \\
$\geqslant 6$ & $0.55(11,52)$ & $0.58(5,35)$ \\
\hline Total & $0.83(108,322)$ & $1 \cdot 1(141,432)$
\end{tabular}

^Adjusted for age, age at menarche, age at first full term pregnancy, history of benign breast disease, family history of breast cancer, and ethnic group.

never used the pill. Among women aged 35 and older there was no evidence that oral contraception affected the risk of breast cancer. In women aged $25-34$ the relative risk for ever users was $2 \cdot 2$ ( $95 \%$ confidence interval $0 \cdot 47$ to $9 \cdot 9)$. Even in this age group the trend in risk with duration of use of oral contraceptives was not significant $(p=0 \cdot 5)$, although the highest risk was in women who had taken the pill for 10 or more years (relative risk $=4 \cdot 6,95 \%$ confidence interval 0.85 to 24.9 ). This was based on eight cases exposed for this period and two who had never used the pill; the corresponding numbers among the controls were 17 and 21 , giving a crude (unadjusted) relative risk of 4.9 . The two unexposed cases and seven of the eight in the longest exposed group were aged $30-34$, so it was not possible to calculate separately the relative risk for women aged 25-29.

As the reference category for women aged 25-34 included only two cases we also estimated risks relative to women who had used oral contraceptives for two years or less or not at all. The adjusted relative risks for the three remaining categories of increasing duration were then $0.64,0.77$, and 1.9 , respectively. The $95 \%$ confidence interval for the last relative risk, in women who had taken oral contraceptives for at least 10 years, was 0.64 to 5.4 .

In further analyses the relative risk associated with duration of use of oral contraceptives was examined by age at, and time since, the start of oral contraception. Table III shows the results for age at first use of oral contraceptives, with risk being expressed relative to the risk for women who had never used the pill. There was no apparent association between age at first use and the risk of breast cancer in any category of duration of use. Similarly, table IV shows no tendency for the risk to increase with time since first use of oral contraceptives. The relative risk of breast cancer in women who had used oral contraceptives for 10 years or longer, having begun 15 or 
more years earlier, was 0.91 (based on 52 exposed cases and 103 exposed controls).

Because of recent suggestions that early use of oral contraceptives might be more relevant than total use to a woman's risk of developing breast cancer we estimated the relative risks associated with duration of use before the first full term pregnancy and before age 25 . Risks were calculated relative to women who had not used oral contraceptives before either the first full term pregnancy or age 25 , regardless of whether they had used them subsequently. Table $\mathrm{V}$ shows the results of these two separate analyses and also gives the numbers of cases and controls in each category of duration of use before the respective event. The relative risks were not increased and actually declined with increasing use of the pill before the first full term pregnancy, and before age 25 , though these trends were not significant $(\mathrm{p}=0 \cdot 14$ and $0 \cdot 4$, respectively)

\section{Discussion}

The results of this national study strongly suggest that the use of oral contraceptives does not influence a woman's risk of breast cancer after the age of 35 . The relative risk was not increased by use before age 25 or before the first full term pregnancy, or by starting the pill before age 20. Moreover, even women who had first taken oral contraceptives more than 15 years previously and had continued to use them for more than 10 years were not at an increased risk. There appeared to be some increase in risk in women in whom cancer was diagnosed before age 35 , but the $95 \%$ confidence interval for the estimate of relative risk in this group was wide and included unity.

The weight that can be given to these findings depends on the design and statistical power of the study. The existence of a National Cancer Registry enabled us to include all eligible cases from the whole of New Zealand. It was then possible to minimise selection bias by using the same criteria for the selection of cases and controls - that the woman's name was in the electoral roll and her telephone number could be found. Response rates were high in both groups, and the cases and controls were interviewed in exactly the same way.

The well established risk factors for breast cancer were apparent in the data, as shown in table I. The results concerning oral contraceptives were not distorted by such factors: there was little evidence of confounding when estimates of relative risk adjusted only for age were compared with estimates adjusted for variables considered a priori to be potentially important confounders. Moreover, adjusting for other variables including menopausal state did not materially affect the results.

The statistical power of this study was high because of the history of exceptionally high pill use by New Zealand women. In 1975 the prevalence of use of oral contraceptives was reported to be higher in New Zealand than in any other country except Holland. ${ }^{8}$ Recent concerp about the safety of oral contraceptives has focused on effects of use at young ages. Of all control women in our study, $48 \%$ had used oral contraceptives before the age of $25(11 \%$ for four years or longer) and $36 \%$ had used them before their first full term pregnancy $(10 \%$ for four years or longer).

From a study of breast cancer in Californian women aged under 37 Pike $e t$ al reported an increased risk in women who had used the pill before the age of $25 .^{3}$ There were further grounds for concern in preliminary results from a British case-control study that showed an increased risk with use of oral contraceptives before the first full term pregnancy (but not with use before age 25$),{ }^{4}$ although an earlier study by the same group had yielded negative results. ${ }^{1+}$ Such an effect was also found in three other studies, ${ }^{5} 1516$ though two of these may have suffered from having small sample sizes and using interview methods that differed for cases and controls. ${ }^{516}$

Our results, which are similar to those of the American cancer and steroid hormone study, ${ }^{6}$ provide no support for the hypothesis that use of the pill at young ages (or before the first pregnancy) increases the risk of breast cancer. Neither prolonged use before age 25 nor prolonged use before the first full term pregnancy was associated with any increased risk of breast cancer, despite our study comprising sufficient numbers of users at young ages for us to examine these questions. If the true relative risk in women taking oral contraceptives for long periods (four years or more) before age
25 was 2.0 we should have had a $99 \%$ chance of declaring a significant result (with two sided $\alpha=0 \cdot 05$ ).

It now seems unlikely, therefore, that the conflicting results of Pike et al and the cancer and steroid hormone study can be reconciled by reference to patterns of pill use in different populations, as was suggested recently. ${ }^{7}$ New Zealand women actually reported a higher prevalence of early use of the pill than the Californian population studied by Pike et al. Of our control women aged under $37,30 \%$ had used oral contraceptives for four years or longer before age 25 , compared with $11 \%$ in the Californian study. ${ }^{3}$ Is there some other explanation for the differing results of the study of Pike et al? The possibility of selection bias in the Californian study was raised by Vessey $e t a^{14}$ when they were unable to replicate the first results published by Pike and his colleagues. ${ }^{17}$ An extreme effect of chance could also have contributed to the differences between studies.

McPherson and Coope recently suggested that the differences between studies might be due to a latent period between exposure to oral contraceptives and development of breast cancer. ${ }^{18}$ Table IV provides strong evidence against such a delayed effect of use of the pill at any age. We performed similar analyses for use of oral contraceptives before age 25 or before the first pregnancy, which also showed no increase in risk many years after use of the pill began. The relative risks in women who had started using oral contraceptives 15 or more years previously (with numbers of cases and controls in parentheses) were $1 \cdot 2(59,123)$ for less than two years' use before age $25 ; 1 \cdot 0(29,83)$ for two to three years' use before age 25 ; and $0.73(8,34)$ for four or more years' use before age 25 .

The one increase in risk in our study was among users of the pill who were aged 25-34 at diagnosis. The highest relative risk was in such women who had used oral contraceptives for 10 years or longer, but the confidence interval was wide and included 1.0 . When the reference group was broadened (because there were only two cases not exposed to the pill in this age group) the relative risks were less impressive. In a cohort study conducted by the Royal College of General Practitioners there was also an increased risk in women under 35, although this was of borderline significance. ${ }^{19}$ As the study of Pike et al was confined to women under 37 the possibility that oral contraceptives affect the incidence of breast cancer only in young women must be considered. The increased risk in young women cannot merely reflect more common exposure to oral contraceptives at young ages in view of the negative results in table V. Indeed, when we analysed separately the data for women under 35 the relative risk was actually lower among women who had started the pill before age 20 than after. The results for the youngest age group in the cancer and steroid hormone study were reported to be affected by more frequent breast examinations (by the woman herself, a physician, or a nurse) among young women taking the pill. ${ }^{6}$ Further work is needed to determine whether such behaviour (leading to earlier diagnosis) could have contributed to our results for women under 35, or to the results of other groups such as Pike and his colleagues.

We may have to wait many years before the final word can be written about the possible carcinogenic effects of oral contraceptives. On present evidence, however, it seems unlikely that they have any appreciable effect on the risk of breast cancer.

This research was supported by a grant from the Medical Research Council of New Zealand. We are grateful for the help of Mrs Celia Harris and Mrs Judith Smeijers (our interviewer and research assistant) and Mr Peter Herbison and Mrs Eileen Moore. We also thank Mr Jim Fraser and Miss Jackie Auld, of the National Cancer Registry, and Associate Professor Ron Kay, Miss Barbara Mason, and Mrs Lorraine Neave, of the Auckland Breast Cancer Study Group. We are grateful to the women who participated in the study and to the surgeons and general practitioners who supported it.

\section{References}

1 Thomas DB. Epidemiologic and related studies of breast cancer etiology. In: Lilienfeld AM, ed. Reviezis in cancer epidemiology. New York: Elsevier North-Holland, 1980:153-217.

2 Kalache A. McPherson K. Barltrop K, Vessey MP. Oral contraceptives and breast cancer. $\mathrm{Br} F$ Hosp. Hed 1983:30:278-83. 
3 Pike MC, Henderson BE, Krailo MD, Duke A, Roy S. Breast cancer in young women and use of oral contraceptives: possible modifying effect of formulation and age at use. Lancet 1983;ii: 926-30.

4 McPherson K, Neil A, Vessey MP, Doll R. Oral contraceptives and breast cancer. Lancet $1983 ;$ ii: $1414-5$.

5 Olsson H, Olsson ML, Möller TR, Ranstam J, Holm P. Oral contraceptive use and breast cancer in young women in Sweden. Lancet 1985;i:748-9.

6 Stadel BV, Rubin GL, Webster LA, Schlesselman JJ, Wingo PA. Oral contraceptives and breast cancer in young women. Lancet 1985; ii:970-3.

7 Anonymous. Another look at the pill and breast cancer [Editorial]. Lancet 1985;ii:985-7.

8 Royal Commission of Inquiry. Contraception, sterilization and abortion in New Zealand. Wellington: Government Printer, 1977.

Mantel N, Haenszel $W$. Statistical aspects of the analysis of data from retrospective studies of disease. Fournal of the National Cancer Institute 1959;22:719-48.

10 Cornfield J. A statistical problem arising from retrospective studies. In: Neyman J, ed. Proceedings of the third Berkeley symposium on mathematical statistics and probability. Vol IV. Berkeley: University of California Press, 1956:135-48.

11 Thomas DG. Exact and asymptotic methods for the combination of $2 \times 2$ tables. Comput Biomed Res 1975;8:423-46.
12 Breslow NE, Day NE. Statistical methods in cancer research. Vol I. The analysis of case-control studies. Lyons: International Agency for Research on Cancer, 1980. (IARC Scientific Publications No 32.

13 Baker RJ, Nelder JA. The GLIM system: generalized linear interactive modelling. Oxford: Numerical Algorithms Group, 1978.

14 Vessey MP, McPherson K, Yeates D, Doll R. Oral contraceptive use and abortion before firs term pregnancy in relation to breast cancer risk. $\mathrm{Br} \mathcal{f}$ Cancer 1982;45:327-31.

15 Paffenbarger RS, Fasal E, Simmons ME, Kampert JB. Cancer risk as related to use of oral contraceptives during fertile years. Cancer 1977;39:1887-91.

6 Harris NV, Weiss NS, Francis AM, Polissar L. Breast cancer in relation to patterns of oral contraceptive use. Am f Epidemiol 1982;116:643-51.

17 Pike MC, Henderson BE, Casagrande JT, Rosario I, Gray GE. Oral contraceptive use and early abortion as risk factors for breast cancer in young women. Br $\mathcal{J}$ Cancer 1981;43:72-6.

18 McPherson K, Coope PA. Early oral contraceptive use and breast cancer risk. Lancet 1986; ;: 685-6.

19 Royal College of General Practitioners. Breast cancer and oral contraceptives: findings in Royal College of General Practitioners' study. Br Med f 1981;282:2089-93.

Accepted 9 September 1986)

\title{
Does short term placebo treatment of chronic schizophrenia produce long term harm?
}

\author{
D A CURSON, S R HIRSCH, S D PLATT, R W BAMBER, T R E BARNES
}

\begin{abstract}
A randomised double blind placebo controlled trial is the most reliable method of assessing putative new developments in medical treatment. In schizophrenia, however, some clinicians believe that relapse contributes to long term deterioration and therefore that patients exposed to either placebo or an inactive new treatment may be put at a disadvantage in the long run if the trial leads to an additional relapse. A seven year follow up of patients included in a randomised placebo controlled trial of fluphenazine decanoate, in which $66 \%$ of the group given placebo relapsed compared with $8 \%$ of those who received the active drug, permitted examination of any long term adverse consequences in those patients who had received placebo. Seventy six $(94 \%)$ of the 81 patients in the original trial were followed up. At the end of the follow up period there were no consistent or important differences in any measure of clinical or social outcome between the patients who had received placebo and those who had received the active drug. This negative finding has implications for the debate on the risk of placebo controlled trials of maintenance treatment in chronic schizophrenia.
\end{abstract}

\section{Introduction}

We set out to determine whether long term harm had resulted from fairly short term placebo treatment and a high relapse rate in the first randomised placebo controlled trial of depot neuroleptic treatment of outpatients with chronic schizophrenia. ${ }^{1}$ During that nine month trial $66 \%$ of the group given placebo relapsed compared with $8 \%$ of the group given fluphenazine decanoate. The clinical question is, What are the long term effects of a single relapse in schizophrenia? A search of previous reports failed to identify any other long term follow up studies of the effects of time limited placebo treatment accompanied by relapse in patients with schizophrenia.

The importance of the randomised double blind placebo controlled trial is well known; it is the quickest and most efficient way of determining the efficacy of an unproved treatment. In one step it eliminates the bias for a particular treatment of both patients and clinicians and bias due to the type of cases selected, placebo effects, and non-specific effects arising during the course of treatment, including the contribution of time in conditions with a tendency to remit over time.

The methods used in the original study were justified because it was not then known how much of the apparent beneficial effect of depot neuroleptics was pharmacological and how much could be attributed to the increased support and supervision provided by changes in environmental factors or in treatment style and approach that were developing.

\section{Patients and methods}

Seventy six (94\%) of the 81 patients with chronic schizophrenia who had entered the original trial were traced; four remained untraced, and one refused interview. Twelve of the 76 patients traced had died. At follow up the mental state of the 64 surviving patients was assessed with the ninth edition of the present state examination ${ }^{2}$; side effects were recorded on an extrapyramidal rating scale devised by Mindham $e t a l^{3}$ and modified by Knights $e t \mathrm{al}^{4}$; social functioning was assessed with the social behaviour assessment schedule ${ }^{5} ;$ and follow up information from case notes and general practice records was recorded on a datasheet of 66 items. A high agreement was achieved between raters on all assessment schedules during training, and this was checked during the study.

In the initial trial social functioning was assessed with a schedule that combined social behaviour and role performance. ${ }^{7}$ The problem of comparing results from different instruments was overcome by adopting a technique used by Brockington $e t a l$, in which two $100 \mathrm{~mm}$ linear analogue 